\title{
Hamsa
}

H眮MSA Journal of Judaic and Islamic Studies

\section{La lexicalización de los nombres bíblicos en la historia del español}

\section{Consuelo García Gallarín}

\section{(2) OpenEdition}

1 Journals

\section{Edición electrónica}

URL: https://journals.openedition.org/hamsa/705

DOI: 10.4000/hamsa.705

ISSN: 2183-2633

\section{Editor}

CIDEHUS - Centro Interdisciplinar de História Culturas e Sociedades da Universidade de Évora

\section{Referencia electrónica}

Consuelo García Gallarín, «La lexicalización de los nombres bíblicos en la historia del español», Hamsa [En línea], 3 | 2017, Publicado el 31 marzo 2017, consultado el 13 mayo 2021. URL: http:// journals.openedition.org/hamsa/705 ; DOI: https://doi.org/10.4000/hamsa.705

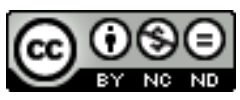

Hamsa est mise à disposition selon les termes de la Licence Creative Commons Attribution - Pas d'Utilisation Commerciale - Pas de Modification 4.0 International. 


\title{
La lexicalización de los nombres bíblicos en la historia del español
}

\author{
Consuelo García Gallarín \\ Universidad Complutense de Madrid \\ gallarin@filol.ucm.es
}

\begin{abstract}
Resumo:
O principal objetivo desta contribuição é o de introduzir uma proposta metodológica para o estudo do léxico dos nomes bíblicos. O campo lexical mais beneficiado por este procedimento tem sido o relacionado com o ser humano. $\mathrm{O}$ conhecimento generalizado de certos episódios e personagens da Bíblia deve-se ao trabalho de professores, pregadores, escritores, tradutores e mesmo dos ditados populares. O virtuosismo de alguns escritores tem contribuído para a descoberta de novas possibilidades de nomeação, seja pela herança latina, seja pela criação independente ou pelo empréstimo.
\end{abstract}

Palavras chave: nome próprio, léxico, epónimo, metodologia, onomástica bíblica

\begin{abstract}
:
The main objective of this contribution is to introduce a methodological proposal for the study of the lexicon from biblical onomastics. The most benefited lexical field by this procedure has been the one related to the human being. The widespread knowledge of certain episodes and characters from the Bible is due to the work done by teachers, preachers, writers, translators, and even by the popular sayings. The virtuosity of some writers has contributed to the discovery of new naming possibilities, because of Latin inheritance, independent creation or loan.
\end{abstract}

Keywords: proper name, lexicalization, eponym, methodology, biblical onomastics

\section{Introducción}

La lexicalización del nombre propio es uno de los principales mecanismos de la lexicogénesis del español ${ }^{1}$. En la actualidad empieza a estudiarse como recurso cognitivo universal $\left.\right|^{2}$. Bruno Migliorini (1968 [1927]) no es el único investigador que aborda este tema ${ }^{3}$,

\footnotetext{
${ }^{1}$ Es sabido que este término abarca los procesos de transformación de distintas unidades lingüísticas en combinaciones idiomatizadas. Los historiadores del léxico han manifestado interés por el estudio de las piezas léxicas formadas por varias palabras y sujetas a distintos grados de lexicalización; así mismo, han podido constatar que este fenómeno debe considerarse como un continuum, así se percibe en los numerosos apreciativos lexicalizados o en los distintos tratamientos de los nombres propios (Nueva Gramática de la Lengua Española, I, Madrid, Espasa Calpe, 2009, p. 57-58.

${ }^{2}$ El estudio comparativo de varios casos de antonomasia en español y chino corrobora la universalidad del procedimiento. Véase Rachid Lamarti, "La antonomasia en las lenguas española y china”, en Actas del II Congreso Ibero- Asiático de Hispanistas, ed. Shoji Bando y Mariela Insúa Cereceda, BIADIG: Biblioteca áurea digital v.27, 2014, p. 291-303.

${ }^{3}$ Magali Fontant ofrece un resumen de las principales contribuciones publicadas antes del diccionario de La Stella: Counson (1907), Migliorini (1927), Tagliavini (1928), Darmesteter (1928), Doutrepont (1929), Peterson (1929), Marouzeau (1950), Monnot (1958), Damourette \& Pichon (1911), Nyrop (1979[1911]), Gougenheim (1972). Véase Magali Fontant, 1998: "Sur le traitement lexicographique: I'antonomase de
} 
pero sí el primer romanista que ofrece una obra monumental desde la perspectiva de la lingüística comparada. A mediados de los años ochenta lo recupera La Stella, autor del Dizionario Storico di Deonomastica (1984). Han seguido esta línea Eva Büchi (1991 y 2002), Magali Fontant (1998), Schweickard (1992 y 1997-2013) y Reinhardt (2010), cuyos trabajos anuncian las nuevas perspectivas de la deonomástica4

La apelativización del nombre propio bíblico responde a distintas intenciones de los interlocutores y a su necesidad de denominar conceptos abstractos o muy específicos por alusión a modelos compartidos; tengamos en cuenta que la religiosidad popular se nutre de tópicos y recursos culturales que han ido afianzándose con puntales hagiográficos, iconográficos y también con la mediación de los exégetas, cuyo rigor estableciendo relaciones quedaba con frecuencia en entredicho, por ejemplo, el sentido negativo del derivado calabriada 'mezcla de varias cosas' se explica por la mala fama de los calabreses, "y que según Lope, Dorotea II,i, se fundaría a su vez en la leyenda de que Judas fue calabrés". ${ }^{5}$

La deonomástica bíblica aborda el tratamiento que reciben destacadas figuras de la fuente, consideradas prototipos de clases de personas, animales, vegetales y cosas. En general, son breves los desarrollos polisémicos y muy limitada la doble aplicabilidad de un mismo epónimo a lo personal y a lo no personal ${ }^{6}$, como es el caso del sustantivo judas:

1. Nombre propio: Judas Iscariote.

2. Nombre bíblico lexicalizado.

El designador alude a un personaje neotestamentario cuya historia es una referencia cultural de contrastada popularidad: Jesús fue vendido por Judas Iscariote a los judíos; arrepentido este de la traición, decidió ahorcarse. En la exégesis de estos episodios se fundamentan las distintas acepciones que el DRAE (2014) recoge:

1.m. Hombre alevoso.

2.m. Gusano de seda que muere colgado sin hacer su capullo.

3.m. Muñeco de paja que en ciertas fiestas se pone en la calle para quemarlo.

El árbol genealógico de acepciones presenta distintos grados de complejidad semántica, según las lenguas. Además del significado compartido, se han producido entre ellas numerosas

nom propre", Cahiers de Lexicologie 73- 2 (1998), p. 5.

${ }^{4}$ La deonomástica estudia los procesos de nominalización, adjetivación y verbalización a partir de los nombres propios. Este término lo introdujo Enzo La Stella, Dizionario Storico di Deonomastica, Bologna, Zanichelli-Olschki, 1984, y lo han aceptado especialistas de reconocido prestigio. Destacan las contribuciones de Eva Büchi, "Contribution à l'étude des déonomastiques galloromans: Index des éponymes dans le FEW", Nouvelle revue d'Onomastique 17-18 (1991), p. 139-152; Eva Büchi, 2002: "Réflexions sur I 'aport de la déonomastique pour la théorie du nom propre: le cas des éponymes à article intégré (domaine roman)", en Onomastik und Lexikographie, Deonomastik, ed. Jean Pierre Chambon et al., Tübingen, De Gruyter, Patronymica Romanica, 2002, p. 171-189. Véanse también Wolfgang Schweickard, 1992: "Deonomastik" (unter vergleichender Berücksichtigung des Italienischen, Rumänischen und Spanischen, Tübingen, Max Niemeyer Verlag, 1992; Wolfgang Schweickard, Deonomasticon Italicum (DI). Dizionario storico dei derivati da nomi geografici e da nomi di persona, 4 vols., Tübingen, Max Niemeyer Verlag, 1997-2013; Magali Fontant, "Sur le traitement lexicographique: I'antonomase de nom propre", p. 5-41; Jan Reinhardt, "El proyecto de un Deonomasticon iberoromanicum", Zeitschrift für romanische Philologie 126 (2010), p. 593-601.

5 Joan Corominas y José Antonio Pascual, Diccionario Crítico Etimológico Castellano e Hispánico, Madrid, Gredos, 1984-1991.

${ }^{6}$ Este tipo de lexicalización supone la conceptualización de una clase. Esta es la principal diferencia entre los sustantivos de origen onomástico y los nombres propios, cuya función principal es designar referentes individuales e inclasificables. Véanse Marie N. Gary -Prieur, Grammaire du nom propre, Paris, PUF, 1994; Kerstin Jonasson, Le nom propre. Constructions et interprétations, Louvain- la - Neuve, Duculot, 1994. 
divergencias: "ser un judas" es 'ser un traidor' en francés, italiano y español, pero solo en esta lengua llaman judas al gusano de seda que "se engancha al subir al embojo y muere colgado sin hacer su capullo" ${ }^{7}$. Una consecuencia de la vulgarización de un relato tan consabido como el de Judas es la multiplicación de locuciones y frases proverbiales, destinadas a validar los hechos narrados. La información que reciben los receptores se somete a un largo proceso de proverbialización de episodios o personajes del máximo interés literario, por ejemplo, la figura de Judas ya destaca en la obra de Berceo:

"Dixí a los judíos: "Parientes e amigos,/ una natura somos de los padres antigos (...) e logredes los cuerpos por qui mucho lazdrastes,/ que soltedes el cuerpo que de Judas comprastes" ${ }^{\prime \prime}$.

El salto cronológico que nos traslada de Berceo a Gonzalo Correas nos ha permitido constatar la nominalización de judas ("falta un judas") y otras posibilidades de tipificación mediante la formación de unidades pluriverbales. En este caso se pormenoriza la conducta del traidor: "el beso de Xudas", "la paz de Xudas", también "alma de Judas" 9 .

"Nunka falta un $X u d a s^{10}$. El beso de Xudas. Dízese del engaño ke se haze por halago ${ }^{11}$.La paz de Xudas. Kuando ai buenas kortesías i malas obras"12 .

En determinados enunciados, el NP clasifica por asociación con un homónimo (1), o por considerarse ejemplarizante el referente inicial (2), o por alteración de la referencia, debida a una relación extralingüística de contigüidad, o de causa- efecto (3), también por designar clases que son definidas por ciertas propiedades del primer portador (4).

(1)Uso denominativo: "e vinieron los Macabeos con todo el pueblo"13.

(2) Uso ejemplar ${ }^{14}$ : "Y un Salomón, que alcanzó y escribió la sabiduría divina y humana"15.

(3) Uso metonímico: "y la postrera púsosela en la boca e dixo un avemaría"16.

(4) Uso metafórico: "y será un tiempo el Moisés, el Josué y el Aarón de su pueblo"17.

En el texto de Larreta la recategorización de los nombres bíblicos posibilita la relación sinonímica: Moisés, Aarón y Josué son prototipos del "guía espiritual".

“Entre el furor y la saña / De tan ingratos Caines" ${ }^{18}$.

\footnotetext{
${ }^{7}$ Diccionario de la lengua española, Madrid, Real Academia, 2014, 23a ed., 2014 (doravante DRAE, 2014)

8 1236- 1246, Gonzalo de Berceo, El duelo de la Virgen, apud Real Academia Española), Banco de datos: CORDE. Corpus Diacrónico del Español. Disponible [en línea] <http://corpus.rae.es/cordenet.html>

${ }^{9}$ DRAE, 2014.

10 1627, Gonzalo Correas, Vocabulario de refranes y frases proverbiales, apud CORDE.

11 1627, Gonzalo Correas, ibíd., apud CORDE.

12 1627, Gonzalo Correas, ibíd., apud CORDE.

${ }^{13}$ c 1200 , Almerich, La fazienda de Ultra Mar, apud CORDE.

${ }^{14}$ Se sigue la clasificación propuesta por Kerstin Jonasson, Le nom propre..., p.182-187, quien ha reconocido diferencias entre el uso ejemplar y el denominado metafórico: con el primero el designador destaca el valor o la función social que se le atribuye a un referente identificado, con el segundo el NP pierde su carácter monovalente y adquiere un valor lexical codificado a partir de ciertas propiedades del referente inicial, no siempre reconocido.

${ }^{15}$ c 1550, Juan de Arce de Otárola, Coloquios de Palatino y Pinciano, apud CORDE.

16 1511, anónimo, Traducción de Tirante el Blanco de Joanot Martorell, apud CORDE.

17 1908, E. Larreta, La gloria de don Ramiro, Argentina, apud CORDE.

18 1822, anónimo, Romances, en Doña Inés de Castro. Pliego suelto, apud CORDE.
} 
La pluralización (caines) y la presencia de determinante o cuantificador (un adán, este jeremías) revelan inequívocamente el cambio categorial. En estos sintagmas se materializa un principio retórico sobre posibles correspondencias ontológicas entre el referente inicial y los de distintos dominios cognitivos. La lexicalización conlleva asociar automáticamente la selección sémica realizada en el referente bíblico con el nombre que lo identifica. Magali Fontant explica el cambio con estas palabras: "il y a lexicalisation lorsque, dans une communauté linguistique donnée, cette sélection sémique se trouve automatiquement et indissolublement liée au nom, de sorte qu'elle peut lui tenir lieu de définition au même titre que celle d'un nom commun" ${ }^{19}$.

Se ha podido constatar que los usos metafóricos aventajan a los metonímicos, estos se reducen a referencias al avemaría, a los libros macabeos ${ }^{20}$, a fitónimos de santoral por asociación cronológica (hierba de san Juan, o del día de san Juan), y a las imágenes en un contexto iconográfico:

"Trajo surtidos de imágenes vulgarísimas, los San Josés por gruesas, los niños Jesús y las Dolorosas a granel y en variados tamaños"21.

Con el presente trabajo se pretende profundizar en el proceso de lexicalización de los nombres bíblicos partiendo de los datos que proporcionan las obras lexicográficas del NTLLE, los principales corpus y los trabajos de destacados especialistas ${ }^{22}$. El repertorio de locuciones y frases hechas permitirá identificar las figuras más populares y valorar el grado de eponimicidad de los nombres que las identifican. Previamente habrá que cumplir los siguientes objetivos:

a) Identificar los factores que propician la construcción de prototipos.

b) Distinguir los epónimos de los falsos epónimos.

\footnotetext{
${ }^{19}$ Magali Fontant, "Sur le traitement lexicographique: I'antonomase de nom propre", p- 7.

${ }^{20} \mathrm{El}$ sustantivo macabeo en ciertos contextos podría ser un caso de metaftonimia, por cruce del doble uso metonímico (libro de los mártires Macabeos) y metafórico (macabeo 'mártir' 'cadáver'). El término metaphtonymy fue acuñado inicialmente por Goossens (1990), lo retoma M. Brdar y R. Brdar-Szabó, "When Zidane is not simply Zidane, and Bill Gates is not just Bill Gates. Some thoughts on the construction of metaphtonymic meanings of proper names, in Aspects of Meaning Construction, eds. G. Radden., K.M. Köpcke, T. Berg y P. Siemund, Amsterdam/ Philadelphia, John Benjamins, 2007, p. 125-142. Trabajos más recientes han seguido la línea de Brdar y Brdar-Szabó sobre la eponimia y la figura del parangón. Véase Ma de los Llanos Carrión Varela, Implementación de reglas de proyección conceptuales en el marco de la semántica profunda para la reutilización de bases de conocimiento enciclopédico, Madrid, UNED,2014. http://e-spacio.uned.es/fez/eserv.php?pid=tesisuned:Filologia-Mlcarrion\&dsID=Documento.pdf 21 1888, Benito Pérez Galdós, Miau.

22 María Ángeles Calero Fernández , "Personajes y episodios bíblicos en las locuciones y frases hechas del español y del catalán”, Paremia 9 (2000), p. 48-60; Ángel Iglesias Ovejero, "Eponimia: motivación y personificación en el español marginal y hablado", BRAE 61 (1981), p. 297-348; Ángel Iglesias Ovejero, "Noms de personnages dans les expressions à nature parémiologique en espagnol: l'exemple de Juan", in Onomastik, ed. D. Kremer, Tübingen, Max Niemeyer Verlag, 2002, p. 269-293; idem: "El árbol paremiológico de Pedro", Anuari de Filologia. Estudis de Lingüística, 5 (2015), p. 79-108. Ricardo Morant, "La secularización lingüística en español”, Iberorromania, 33 (1991), p. 58-73.

RAE, Banco de datos: CORDE. Corpus Diacrónico del Español. Disponible [en línea] <http://corpus.rae.es/cordenet.html>

RAE, Banco de datos: CREA. Corpus de Referencia del Español Actual Disponible [en línea] $<$ http://corpus.rae.es/cordenet.html>

RAE, Nuevo Tesoro Lexicográfico de la Lengua Española (NTLLE). Disponible [en línea] < http://ntlle.rae.es/ntlle/SrvltGUILoginNtlle>
} 
c) Explicar por qué se han internacionalizado determinados epónimos bíblicos: judas 'traidor' (fr. judas, port. judas, it. giuda, ing. judas) y otras acepciones.

d) Delimitar la deonomástica popular respecto de la culta.

e) Localizar los campos léxicos que más se han beneficiado del procedimiento y observar las tendencias derivativas.

f) Hacer una propuesta de periodización respecto de la lexicalización de los nombres de personajes bíblicos.

\section{Factores que coadyuvan a la construcción de prototipos}

El conocimiento generalizado de las principales historias y de sus protagonistas se debe a la labor de oradores, literatos, traductores ${ }^{23}$ e incluso a la iniciativa del vulgo que sentencia con paremias. La ejemplaridad se aprende a través de la palabra y la imagen. La oratoria sagrada, la hagiografía y la iconografía contribuyen a avivar el fervor de los participantes en festividades religiosas de enorme raigambre popular; las que más invitan a la participación son la Semana Santa, las fiestas patronales o las romerías ${ }^{24}$, en las que nunca falta la intervención de un predicador. Gran parte de los usos analizados provienen de la literatura ascética y mística de fray Luis de León y san Juan Bautista de la Concepción, de los sermones de fray Alonso de Cabrera y Miguel Ruiz, del Vocabulario de refranes de Gonzalo Correas, y también de la obra literaria de autores barrocos, principalmente de Lope de Vega, Francisco de Quevedo, y Francisco López de Úbeda ${ }^{25}$. El arte, el didactismo y lo festivo se han aliado para que los héroes y antihéroes ocupen un espacio destacado en el imaginario colectivo; de este modo la población analfabeta ha ido aprendiendo los nombres que no podía leer. Las imágenes siempre han alimentado el recuerdo de los hechos extraordinarios, al ir asociadas a un discurso de tipo enciclopédico en el que no faltan rasgos prominentes:

La Eva preludia aquellas hembras buonarrotescas hercúleas; el Josué hace honor a su atavío clásico; la Judit resulta apocada, y el Abraham, inerte; el Bautista ya sabemos que parece un eco del de Siloé; el Adán cede a lo pintoresco su debida grandeza, y el David es como hembra; pero el punto flaco son los santos con vestiduras de ritual ${ }^{26}$.

Las figuras se recuerdan por los atributos que las acompañan: animales, objetos evocadores del martirio sufrido, entre otros motivos. Las imágenes mentales de los protagonistas de ciertos episodios han propiciado su conversión en prototipos de la conducta humana. La lexicalización suele pasar por una fase previa de popularización del referente inicial a diferencia de los usos discursivos de la lengua elaborada, creados para ser leídos y con otra intencionalidad más erudita y exigente, por ello es conveniente comparar el tratamiento que

\footnotetext{
${ }^{23}$ Luis Alonso Schökel y Eduardo Zurro, "Mis fuentes están en ti". Estudios bíblicos de literatura española, Madrid, Universidad Pontificia de Comillas, 1998.

${ }^{24}$ Manuel Martín Sánchez, Seres míticos y personajes fantásticos españoles, Madrid, Edaf ensayo, 2002.

25 a.1598, Fray Alonso de Cabrera, Consideraciones sobre los Evangelios de los domingos, Madrid, BaillyBaillère, 1906; a.1617, Miguel Ruiz, Sermón de la Inmaculada Concepción de la Virgen María, Sevilla, Ayuntamiento de Sevilla, 1992; c1610-1612, san Juan Bautista de la Concepción, Exhortaciones y pláticas, a la perseverancia, Madrid, Editorial Católica, 2002; a. 1583, fray Luis de León, De los nombres de Cristo, libros I-III, Oviedo, Universidad de Oviedo, 1996; a.1597-1645, Francisco de Quevedo y Villegas, Poesías, Madrid, Castalia, 1969-1971; a. 1605, Francisco López de Úbeda, La pícara Justina, Madrid, Editorial Nacional, 1977; a.1612, Lope de Vega Carpio, Pastores de Belén, prosas y versos divinos, Barcelona, PU, 1991.

${ }^{26}$ Manuel Gómez Moreno, Las águilas del Renacimiento español: Bartolomé Ordóñez, Diego Siloé, Pedro Machuca, Alonso Berruguete, apud CORDE.
} 
han recibido los nombres bíblicos y observar las características de las fuentes que los emplean como apelativos, así como las vías de transmisión de este tipo de léxico. Para diferenciar los usos propios de los importados es recomendable identificar las acepciones coincidentes en dos o más lenguas y separarlas de las exclusivas de un único dominio lingüístico, por ejemplo, el sustantivo judas, además de significar 'traidor', ha desarrollado en francés la acepción "trampa en el suelo para oír o ver lo que hacen los del piso inferior"27, a diferencia del español. La destreza de algunos escritores no solo ha contribuido a la consolidación de un uso sino al descubrimiento de nuevas posibilidades denominativas, sea por herencia latina, por creación independiente o por préstamo; por ello es recomendable distinguir entre léxico heredado, léxico adquirido y léxico multiplicado ${ }^{28}$, como método diferenciador de los préstamos respecto de otras iniciativas internas, igualmente innovadoras: magdalena 'mujer penitente' (ing. magdalene, port. madalena, fr. madeleine, it. maddalena), entre varias acepciones. Estos y otros epónimos ponen de manifiesto que la Biblia fue fuente de inspiración en toda la Europa cristiana, tanto para los doctos como para los iletrados que escuchaban los usos lingüísticos de sus líderes, los imitaban y también los reinterpretaban.

El español americano concuerda con el europeo en la lexicalización de ciertos antropónimos ${ }^{29}$.

BENJAMíN. 1. M. y F. 'Hijo menor', como Benjamín, hijo último y predilecto de Jacob (DRAE). Integrado en italiano, francés y en otras lenguas rom $^{30} 2$. m. Miembro más joven de un grupo. El CORDE proporciona bastantes testimonios de España y América (Argentina, Nicaragua, México y Colombia), los más antiguos pertenecen a textos del siglo XVII.

DOC.HIST. ESPAÑA. Llámalos benjamines, hijos regalados ${ }^{31}$, Las Racheles de tantos Benjamines $^{32}$.

DOC. HIST. AMÉRICA. Benjamines que, si nacen,/ es porque matan atroces ${ }^{33}$, Saras viejas y adolescentes Benjamines ${ }^{34}$.

\footnotetext{
${ }^{27}$ Joan Corominas y José Antonio Pascual, Diccionario Crítico Etimológico Castellano e Hispánico.

${ }^{28}$ Pertenecen al léxico heredado los días de la semana referidos a un dios: martes (del latín Martis [dies]), en Léxico Hispánico Primitivo. Siglos VIII-XII, por Menéndez Pidal et al., Madrid, Real Academia Española Fundación Ramón Menéndez Pidal, 2003. El español también podría haber importado voces pertenecientes a la deonomástica bíblica; por ejemplo, faire la Madelainne (Trésor de la Langue Française informatisé - http://atilf.atilf.fr/; doravante TLFi), Mathusalem (TLFi) preceden a los correspondientes usos deonomásticos del español: magdalena 'mujer penitente' y matusalén 'hombre muy longevo'. No faltan las creaciones propias; por ejemplo, José Caifás es el prototipo del hombre malvado en Bolivia, y en México, Guatemala y Nicaragua se expresa el deseo de que sea pagada una deuda con la interjección ¡Caifás!, registrada en Asociación de Academias de la Lengua Española - Humberto López Morales (dir.), Diccionario de Americanismos, Madrid, Santillana Ediciones Generales, 2010.

${ }^{29}$ Se han consultado otros diccionarios de americanismos: Günther Haensch y Reinhold Werner (dir.), Nuevo Diccionario de Americanismos. Nuevo Diccionario de Colombianismos, coord. por Claudio Chuchuy y Laura Hlavacka, Bogotá, Instituto Caro y Cuervo, 1993; Günther Haensch y Reinhold Werner (dir.), Nuevo Diccionario de Americanismos. Nuevo Diccionario de Uruguayismos, coord. por Úrsula Kühl de Mones, Bogotá, Instituto Caro y Cuervo, 1993; Günther Haensch y Reinhold Werner (dir.), Diccionario del español de Cuba. Español de Cuba- español de España, coord. por Gisela Cárdenas Molina y Antonia María Tristá Pérez, Madrid, Gredos, 2000; Günther Haensch y Reinhold Werner (dir.), Diccionario del español de Argentina - español de España, coord. por Claudio Chuchuy, Madrid, Gredos, 2000; Lara, Fernando (dir.), Diccionario fundamental del español de México, México, Fondo de Cultura Económica, 1993.

${ }^{30}$ Bruno Migliorini, Dal nome proprio al nome comune: studi semantici sul mutamento dei nomi propri persona in nomi comuni negl'idiomi romanzi, Firenze, Leo S. Olschi Editore, 1927.

${ }^{31}$ c 1603-1607, San Juan Bautista de la Concepción, Pláticas a los religiosos.

32 1609, Lope de Vega Carpio, Jerusalén conquistada.

${ }^{33}$ a 1659, Hernando Domínguez Camargo, Otras flores aunque pocas, Colombia.

34 1914, Rubén Darío, Canto a la Argentina y otros poemas, Nicaragua.
} 
CAIFÁS. 1. M. fig. Persona que obra con maldad. 2. Niño muy travieso ${ }^{35}$. La primera acepción pertenece a distintas variedades del español, pero la segunda solo se ha localizado en textos de Bolivia y de Colombia.

"Las malas compañías pervierten hasta los santos, y aquí hay mucho zambito malcriao y mucha gente mala, aunque no tanto comu'en Orofino. Por eso no lu'hemos puesto en l'escuela, porque se vuelve comu'el caifás de Damiana y aprende muchos dichos feos y se pone como la gentuza." ${ }^{36}$

En los diccionarios citados, las acepciones exclusivas son escasas, pero no descartamos el hallazgo de nuevas muestras de variación. Además de las voces coincidentes en la forma y el significado, habrá que identificar los usos que son propios de determinadas variedades del español (una Ana profetisa) o aquellos con desarrollos semánticos independientes.

JUDAS. De nuevo la historia del apelativo judas da muestras de la diversidad del tratamiento: es panhispánica la acepción ya comentada de 'hombre alevoso y traidor', por alusión a Judas Iscariote, pero pertenecen al español de América las acepciones de 'policía' ${ }^{37}$ y 'político'.

DOC. CONT. "Puro fingimiento todos: políticos, iniciativos privados, paisas. Mire: ¿le dije que se había acabado la materia prima pa los Judas, o sea los políticos iscariotes? Jijos, judas los hay como nunca, y eso lo sabemos todos por más que el denunciarlo se haiga vuelto bandera de periodistas" ${ }^{\prime 38}$.

No todos los usos discursivos, previos a la lexicalización, responden a la misma motivación y sensibilidad. A menudo, entre el nombre y ciertos rasgos característicos del referente originario se produce "una conexión laxa" ${ }^{39}$, puesto que la corriente docta no siempre comparte los tópicos populares. En el diasistema del español varían el grado de polisemia de los nombres bíblicos lexicalizados y la distribución geográfica de las locuciones que estos forman; así, la expresión patrimonial manzana de Adán 'nuez de la garganta' es propia del español americano ${ }^{40} y$ traduce el inglés Adam's Aple. Un mismo concepto puede expresarse con palabras derivadas de bases diferentes, según la variedad del español.

\section{El problema de la identificación de los referentes bíblicos: verdaderos y falsos epónimos. Otros casos de variación eponímica: Judas o Iscariote}

El investigador debe evitar errores etimológicos ante la posibilidad de que se confundan referentes homónimos; se ha de considerar si la propuesta no es una conjetura sino un hecho probado. No pertenecen al léxico de los nombres bíblicos los que proceden de portadores sin vinculación con los textos sagrados. Son nombres de clases de personas (maría, mariquita, juan, donjuán), de animales y plantas (perico, don pedro o dompedro), también de cosas: sara 'pastelillo', por alusión a Sara Bernard y no al personaje bíblico. En estos casos, los referentes iniciales ya no guardan relación con la fuente objeto de estudio, son homónimos representativos

\footnotetext{
35 Nicolás Fernández Naranjo, Diccionario de bolivianismos, La Paz, Cochabamba, Los Amigos del Libro, 1980.

36 1935-36, Tomás Carrasquilla, Hace tiempos, Colombia.

${ }^{37}$ Renaud Richard, Diccionario de hispanoamericanismos no recogidos por la Real Academia, Madrid, Cátedra, 2006.

38 1985, Tomás Mojarro, Yo, el valedor, México, apud CORDE.

39 Alfonso García Suárez, Modos de significar. Una introducción temática a la filosofía del lenguaje, Madrid, Tecnos, 1997, p. 111-112.

${ }^{40}$ Tomás Buesa Oliver y José María Enguita Utrilla, Léxico del español de América: su elemento patrimonial e indígena, Madrid, Editorial MAPFRE, 1992.
} 
de una clase social, de ahí el sentido genérico que pueden transmitir en referencias personales: los juanes, las marías, los pedros ${ }^{41}$. Los juanes que dieron nombre a los juanetes no guardan relación con los homónimos históricos (Juan el Bautista, Juan el Evangelista), tampoco los Pedros con hipocorísticos como perico o periquito.

"Preguntado que por qué había tantos Juanes necios, respondió: "Porque los más de los hombres lo son, y hay muchos que se llaman Juanes." 42 "Este es un proverbio que solemos usar comúnmente para dar a entender la multitud de algunas cosas que ay dondequiera. Mas no sabemos ni se entiende por qué se dize más Bartolomicos que otra cosa. Pues de nombres de Juanes, Pedros y Françiscos y otros suele aver más." ${ }^{43}$

La univocidad y la multivocidad del NP refuerza la oposición entre lo específico: "un barrabás", "un cirineo" y lo genérico: "un juan", "un bartolo". Como se ha explicado, las dos últimas nominalizaciones no remiten a una figura bíblica, sino a personajes proverbiales: Bartolo en lugar de Bartolomé: "ser un bartolo".

Una dificultad adicional es el doble tratamiento denominativo, cuando los primeros portadores poseen nombre múltiple: Judas Iscariote es el arquetipo de los iscariotes y también de los judas, los dos antropónimos designan al 'hombre alevoso y traidor', pero el DRAE (2014) solo reconoce un uso.

Siglo XVII: "Librándome de la furia de aquel su Escariote" ${ }^{44}$, "es razón que la llamen doña Escariote"45.

Siglo XIX (América): "Mas en vez de eso, hubo un Judas, y no un Iscariote cualquiera, sino un conspicuo y titulado" ${ }^{46}$.

La referencia a María Magdalena no se abrevia con regularidad: "una romántica Palidez de Marías Magdalenas" ${ }^{47}$, pero también "Dejad las Magdalenas y las Martas" ${ }^{48}$. La variación no es exclusiva de los nombres bíblicos, se produce siempre que el personaje se ha popularizado con más de un nombre: un Sancho ${ }^{49}$ o un Sancho Panza ${ }^{50}$.

\section{Eponimia popular y eponimia culta}

Es inevitable preguntar por qué unos nombres propios se lexicalizaron antes que otros, por qué unos referentes iniciales son más representativos de la eponimicidad, incluidos los lugares que han recibido tratamiento metafórico (babel, belén, calvario). Los interesados en seguir esta línea de

\footnotetext{
${ }^{41}$ La profesora Elena Bajo Pérez ha profundizado en esta cuestión. Reconoce que "es difícil distinguir entre los casos de antonomasia propiamente dicha y los progenéricos", estos, según Bajo, comienzan siendo designaciones burlescas" - Elena Bajo Pérez, La caracterización morsintáctica del nombre propio, A Coruña, Toxosoutos, 2002, p. 70; Ángel Iglesias Ovejero, "El árbol paremiológico de Pedro", Anuari de Filologia. Estudis de Lingüística 5 (2015), p. 79-108; José Luis Alonso Hernández y Javier Huerta Calvo, Historia de mil y un Juanes. Onomástica literaria y folclore, Salamanca, Universidad de Salamanca, 2000.

42 1596, Juan Rufo, Las seiscientas apotegmas, apud CORDE.

43 1570-1579, Sebastián de Horozco, Libro de los proverbios glosados, apud CORDE.

44 1602, Diego Alfonso Velásquez de Velasco, El celoso.

451629 - 1630, Francisco de Quevedo y Villegas, Libro de todas las cosas y otras muchas más.

46 1899, Argüello Mora, Manuel, La Trinchera, Costa Rica.

47 1909, Leopoldo Lugones, Lunario sentimental, Argentina, apud CORDE.

48 1640, Capitán Castro de Torres, Panegírico al chocolate, apud CORDE.

49 1875, Ricardo Palma, apud CORDE.

50 1892, Fernández y Medina, apud CORDE.
} 
investigación tendrán que ordenar la relevancia tipológica, teniendo en cuenta los primeros indicios de vulgarización de la historia y la condición social de las personas que han propiciado el cambio categorial como líderes lingüísticos, principales responsables del triunfo del epónimo, sean literatos, predicadores, escultores, pintores o representantes del vulgo. Conviene precisar que este mecanismo de la lexicogénesis se convirtió en un recurso del gusto de los iletrados, que asimilaron pronto fórmulas ensayadas por los cultivadores del arte de escribir. Ha de tenerse en cuenta que estos fueron ampliando el repertorio de arquetipos con figuras que ocasionalmente representaban categorías sociales y morales, sin embargo, sus nombres no aparecen en las obras lexicográficas con un valor lexical porque no llegaron a vulgarizarse: una Abigail, un Absalón, un Josué, un Matatías, etc.

"Cesen de las mujeres mas fieles

Sus justas alabanzas mas que humanas;

Callen ya las Rebecas y Raqueles,

Las Délboras, Esteres y Susanas,

Sáras, Abigailes y Jaeles,

Bellas Judiches, venerables Anas,

Pues son con tu grandeza milagrosa

Como es el mirto con la palma hermosa" ${ }^{51}$

Abundan en la literatura española de los siglos XVI y XVII: otro Abraham, otro Aarón, otro Jacob, otra lerusalem, otra Raquel, otra Sara, otra Judith, etc., nombres que no han llegado a entrar en el diccionario académico, salvo los que forman locuciones: "seno de Abraham", "cruz de Jerusalén", "lágrimas de Moisén" o "lágrimas de Moisés"52.

La etimología popular y el malapropismo frente a la corrección formal en el tratamiento del nombre propio originario son indicios de la vulgarización del cambio. La coexistencia de variantes (una Délbora y una Débora) y la opacidad etimológica de voces que podrían tener un origen onomástico evidencian fluctuantes tratamientos (Moisés y Moisén; en francés Macabré o Macabé). Desconcierta la relación del adjetivo macabro con los Macabeos, no solo por la presencia o ausencia de la vibrante sino por ser importación del francés dance Macabré o Macabé 'danza de la Muerte', tal vez por alusión a su martirio.

El repertorio de los personajes bíblicos es más reducido en la lengua popular, por ejemplo, entre todos los Judas del Nuevo Testamento solo uno ha dado nombre a un tipo de persona. Esta limitación no es propia de los eruditos ávidos de experimentación verbal, pues son ellos los más audaces a la hora de escudriñar las similitudes más recónditas y de ampliar la galería de tipos personales mediante metáforas discursivas. Solo los doctos pueden interpretar individualmente las fuentes que el vulgo no puede explorar. La lexicalización conlleva la construcción de un modelo a partir de los rasgos más destacados, fácilmente reconocibles por gran parte de los hablantes, pero los usos discursivos son el resultado de iniciativas lingüísticas más libres e independientes, pertenecen a la lengua más elaborada y representan la primera fase de dicho proceso, cuando todavía se necesita información adicional para interpretar correctamente el significado de la palabra de origen onomástico.

"Mas como soy de inclinación humilde, de profesión pícara, de cuidado ajena, y como ni viven Saúles ni Samueles, determiné carecer de la expectativa y actión que podía tener por este camino a ser reina." ${ }^{53}$

\footnotetext{
${ }^{51} 1604$, José de Valdivielso, Vida, excelencia y muerte del gloriosísimo patriarca San José, apud CORDE.

52 DRAE, 2014.

53 1605, Francisco López de Úbeda, La picara Justina, 375.
} 
Sin el conocimiento de la historia de Samuel y Saúl sería imposible interpretar la alusión en este discurso picaresco. Los Saúles eran los elegidos y los Samueles los jueces con capacidad de elegir. A diferencia de los usos cultos, el repertorio de héroes y antihéroes en la deonomástica popular lo constituye un reducido número de figuras. Son especialmente recordados Abel, Caín, Barrabás, Judas, Salomón, Sansón y la Magdalena. Es posible que el mismo concepto reciba el nombre de varios referentes modélicos, aunque no todas las palabras hayan entrado en los diccionarios, por ejemplo, Matusalén ha ganado a Abrahán, igualmente mencionado en libros de paremias: "Ni tan viexo Abrahán, ni tan niño Xesús"54. Los modelos se extraen de las historias más comentadas y permiten tratamientos eufemísticos (una magdalena 'prostituta' 55 , disfemísticos (matusalén 'hombre muy longevo') e hiperbólicos (sansón 'hombre muy forzudo').

La presencia de los personajes bíblicos en la fraseología ha sido analizada por Ma Ángeles Calero $^{56}$, quien retoma los resultados obtenidos por investigadores que han establecido las bases de la investigación sobre la deonomástica en España, entre ellos Iglesias Ovejero y Morant Marco ${ }^{57}$. Sigue esta línea el equipo DEONOMA de la $\mathrm{UCM}^{58}$. Ma Ángeles Calero ofrece bastantes testimonios del uso sustantivo de Adán, Judas, Magdalena, Matusalén, Salomón, Jeremías, Lázaro, Sansón, Barrabás, Moisés, Verónica, Herodes, San Pedro, Belén y Jordán, en referencias personales y no personales, así mismo, forman locuciones y frases hechas: Adán, Caín, Judas, Magdalena, Salomón, Sara, Lázaro, Jacob, Job, Noé, Abrahán, David, Herodes, aunque no todas se encuentran en el diccionario académico: Más vieja que Sara. El parto de Sara. La escala de Jacob. El sueño de José59. Si se atiende al número de variantes que cada referente ha generado en el lenguaje paremiológico, tendremos que establecer el siguiente orden de productividad: Adán (13, en Calero, 2000: 57-58), Judas (10), Magdalena (10), Caín (9), Matusalén o Matusalem (6), Salomón (6), Jeremías (6), Lázaro (6), Job (5), Noé (4), Sansón (4), Abrahán o Abraham (3), Barrabás (3), David (3), Moisés (2), Verónica (sustantivos no personales, 2), Berenice (1), Herodes (2), Sara (1), Jacob (1), San Pedro (planta) (1). Sobre otros episodios del Nuevo Testamento: Belén (2), Jordán (1).

María Magdalena, Barrabás, Caín, Goliat, Judas y Jeremías, entre otros muchos, son prototipos que se definen igualmente en francés, español e italiano ${ }^{60}$. Migliorini y La Stella confirman la convergencia (1) sin que ello haya impedido otros desarrollos exclusivos de una sola lengua (2).

(1) Caín 'cruel', Goliat 'gigante' despectivo en la Edad Media, por ser protector de clérigos pícaros.

(2) Un ejemplo de usos propios o internos es el francés davier o daviet 'ganzúa'61.

En expresiones metafóricas no es obligada la coincidencia de género entre comparante y comparado, pero con los nombres bíblicos los designadores no se permiten demasiadas licencias, y tanto las metáforas como las metonimias deonomásticas suelen seleccionar el mismo género que el referente inicial. Difieren benjamín y bejamina o jeremías ( $m$ y f), según el DRAE (2014), pero coinciden barrabás (m), lázaro $(\mathrm{m})$, judas $(\mathrm{m})$, magdalena (f), entre otros. Con los topónimos se ha

\footnotetext{
54 1627, Gonzalo Correas, Vocabulario de refranes y frases proverbiales

55 "Allí los pilluelos de la calle, las muchachas del arroyo, las magdalenas" (C.M.de Heredia, Una fuente de energía, México, 1932, apud CORDE).

${ }^{56}$ Ma Ángeles Calero, "Personajes y episodios bíblicos en las locuciones y frases...".

${ }^{57}$ Más información en la nota 6.

58 Jorge Braga Riera (coord.), La suerte de los nombres propios, Madrid, Sílex, 2012.

59 Datos de Calero, Ma Ángeles Calero, “Personajes y episodios bíblicos en las locuciones y frases...", p. 4960.

${ }^{60}$ Bruno Migliorini, Dal nome proprio al nome comune...

61 TLFi.
} 
impuesto el género semántico a partir de la asociación de conceptos nucleares: lío (m. galimatías); confusión, desorden (babel, f. y m. respectivamente), lugar (m. calvario).

\section{Campos en que se inscribe el léxico deonomástico de origen bíblico}

Con el fin de hacer una propuesta bien fundamentada sobre las motivaciones que han propiciado la aceptación de estas palabras, se propone ordenar por temas los nombres bíblicos lexicalizados. Este método facilita la identificación de los mecanismos de tan peculiar neología. Los literatos han rentabilizado al máximo los recursos retóricos de la metáfora y la metonimia por los variados efectos a los que nos hemos referido, aunque los hablantes iletrados también supieron aprovecharlos, siguiendo las pautas de la oratoria sagrada, la paremiología y el lenguaje literario más cercano, por ejemplo, el del teatro. Predominan las asociaciones unidireccionales (de lo personal a lo personal) respecto de las asociaciones indirectas o cruzadas (de lo personal a lo no personal y viceversa).

\section{De los personajes bíblicos a las clases de personas}

En la España del periodo clásico, la Biblia y las vidas de santos fueron canteras inagotables de las cuales se podían extraer modelos ejemplarizantes. Estas fuentes facilitaron la ampliación de la galería de tipos personales, cuando se trataba de profundizar en la conducta del ser humano y en sus circunstancias. En apartados anteriores se han mencionado algunas correspondencias entre tipos humanos y personajes bíblicos: además del hombre traidor (Judas) y el hombre muy longevo (Matusalén), se suman al repertorio las figuras del hijo menor (Benjamín), la mujer arrepentida (María Magdalena), el hombre malvado o díscolo (Barrabás), el hombre descuidado (Adán), el hombre cruel con los niños (Herodes), entre otros. La lexicalización conlleva la implantación de un modelo claramente simplificado respecto de la complejidad del primer portador del nombre, no obstante, los usos discursivos o neológicos sorprenden al receptor en el Barroco y con frecuencia se suman a un retoricismo que administra la erudición poniéndola al servicio del ingenio. Los ejemplos que se citan a continuación pertenecen a La pícara Justina:

DAVID es el prototipo del hombre que destaca por su valentía y clarividencia. Falta en el DRAE, que solo registra estrella de David -símbolo del judaísmo - y lágrimas de David 'planta'.

"Si él fuera un David, no temiera, que los Davides y los corteses sólo tiran piedras a los gigantes y no a damas." ${ }^{\prime 2}$

SALOMÓN: m. Hombre de gran sabiduría, por alusión a Salomón, rey de Israel y de Judá, hijo de David. También "sello de Salomón"63.

"Yo los llamara segundos Urías y Salomones, pues por haber dado insigne templo y casa de descanso a Dios, carecen del suyo propio." ${ }^{64}$

Se exprimen todas las posibilidades de actualización de la ejemplaridad del modelo. Los homónimos que lo reproducen ya no son seres únicos sino clases de personas. En los desvíos metafóricos se producen discordancias de género entre $A$ y $B$, tal vez porque se contemplan de forma global comparante y comparado. "A sus pies me humillo hecho otra Madalena"65.

\footnotetext{
62 1605, López de Úbeda, La pícara Justina, 370, apud CORDE.

${ }^{63}$ DRAE, 2014.

64 1605, López de Úbeda, La pícara Justina, 325, apud CORDE.

65 1604, Gregorio González, El guitón Onofre, Logroño, Consejería de Cultura de la Rioja, 1995, p.194.
} 


\section{De lo personal a lo no personal}

Con la práctica de las metáforas y metonimias cruzadas en el Siglo de Oro comienza una etapa de ampliación y complejización de este recurso retórico. Los nombres bíblicos se emplean con prodigalidad en la formación de fitónimos pluriverbales: "Aaron ierva o barva de aaron. arus .i." ${ }^{66}$. Además de la "hierba de Aarón" ${ }^{67}$, se conocen "el árbol de Judas" ${ }^{68}$, "la hierba de san Juan"69, "la hierba de santa María"70, incluso "la hierba de Tierra Santa"71, "la hierba de San Pedro", "la hierba de San Pablo", "la hierba de Santiago"72. Las locuciones HIERBA DE + NP y ÁRBOL DE + NP son propias de la lengua popular y aluden a ritos o leyendas que atribuyen propiedades curativas o mágicas a determinadas plantas.

“Porke están seguras de bruxas, según opinión de muxeres, si las koxen la mañana de San Xuan. lervalán pareze dezir ierva de San Xuan, korrutamente." ${ }^{73}$

El cruce referencial que consiste en el paso de lo personal a lo no personal no es exclusivo del español, una muestra de la internacionalización de este tipo de juegos semánticos la tenemos en la palabra moisés "cestillo ligero de mimbre que sirve de cuna portátil" (fr. moïse). No se descarta que sea un galicismo, pues son anteriores los testimonios escritos en francés, en los que se alude al personaje bíblico que fue encontrado en un cestillo por la orilla del Nilo ${ }^{74}$. La misma lengua conoce el sustantivo popular balthazar (de Balthasar o Baltasar) 'banquete'.

\section{Los referentes bíblicos no personales y su relación con la experiencia humana}

El español clásico es un periodo fecundo en juegos etimológicos. En el léxico deonomástico cabe señalar la elección de voces que admiten interpretaciones metonímicas y metafóricas, por ejemplo, ciertos referentes no personales -lugares principalmente- dan nombre a fenómenos en los que interviene el hombre: Babel, Babilonia, Belén, Edén, Jerusalén, Jordán, Gehena, Calvario o Gólgota. Estos lugares remiten a sucesos similares a los que allí ocurrieron: babel, nombre bíblico de Babilonia 'desorden y confusión', coincidiendo con el italiano y otras lenguas iberorrománicas - en francés solo babélisme y babélique ${ }^{75}$, pero en cualquier caso la metáftonimia se sustenta en la narración bíblica (Génesis XI-9). En el español antiguo rivalizan babel y babilonia: "Era una Babilonia. Por: kosa de gran konfusión" ${ }^{76}$. Las dos palabras contienden en determinados contextos con belén 'sitio en el que hay mucha confusión', 'confusión', de donde "se armó el Belén".

Un caso interesante es el latín Calvarium, que traduce el griego Golgotha, y este del arameo. En italiano, francés, rumano y las lenguas iberrománicas, Calvarium ha recibido el sentido traslaticio de 'sufrimiento', y con el mismo valor se emplea en el español contemporáneo la palabra Gólgota, aunque el uso no ha superado el nivel discursivo: "Zuloaga, logró revivir en su oratorio, un Gólgota sangrante de dolor" ${ }^{77}$. En los principales corpus del

\footnotetext{
66 1495, Antonio de Nebrija, Vocabulario español-latino.

67 1962, Font Quer, apud CORDE.

${ }^{68}$ DRAE, 2014.

69 1627, Correas, apud CORDE; DRAE 2014.

70 1527-1561, Fray Bartolomé de las Casas, apud CORDE.

71 1908, Galdós, apud CORDE.

72 1962, Font Quer, apud CORDE.

73 1627, Gonzalo Correas, Vocabulario de refranes y frases proverbiales, apud CORDE.

${ }^{74}$ TLFi.

75 Enzo La Stella, Dizionario Storico di Deonomastica, p. 31-32.

${ }^{76}$ CorreasVR, 625.

77 1969, Iñaki Linazasoro, La otra Guipúzcoa.
} 
español aparecen más testimonios de nombres bíblicos recategorizados, por ejemplo, el topónimo Jerusalén y el hidrónimo Jordán:

"Pues aquella casa, en reliquias preciosas, es una Jerusalén" 78.

"Se desmiente en un Jordán/ que ondas de tinta lleva"79.

En el Barroco la exageración es casi la norma, y la burla es una consecuencia de las actitudes más ligadas a la estética de la desmesura y la irreverencia, a menudo lograda por la paronimia. La percepción que se tiene de un nombre depende en parte de la similitud de este con otras palabras ${ }^{80}$.

"Calvino, Calvatrueno, calva Anás,/ calva de Herodes, calva de Caifás;/

calavera del diablo, al campanario/ con tu calva le haces un Calvario" 81.

Gran parte de las metáforas inspiradas en referentes bíblicos se prestan al juego de palabras, a la hipérbole y al humorismo (calva/calvario); por la misma razón, el italianismo lazareto es un caso interesante de opacidad etimológica por múltiples factores. Spitzer sostiene que la palabra viene en realidad de Nazareth, si bien alterada por influjo de Lázaro ${ }^{82}$.

\section{Categorías deonomásticas: nominalización, adjetivación y verbalización}

$$
\mathrm{NP} \rightarrow \mathrm{N}(\mathrm{NP}->\mathrm{N}->\mathrm{N}) \text {. }
$$

A diferencia de otros procesos de nominalización, la contienda entre sufijos rivales es irrelevante en el léxico objeto de estudio ${ }^{83}$. Es productivo el sufijo-ADA. Se emplea con el significado de 'acción propia de' (jeremiada) y 'acción perjudicial' (barrabasada).

NP $\rightarrow$ ADJ.

El sufijo -ITA resulta más rentable cuando la base es un nombre bíblico ${ }^{84}$. Las formaciones internas siguen un modelo establecido en latín: levita (del It. tardío levīta). Pharies ${ }^{85}$ ha señalado los antecedentes de estas palabras y ha descrito la evolución del sufijo, desde los gentilicios hasta los nombres de los seguidores de ciertas figuras patriarcales. EI DRAE contiene: aaronita, amalecita, amonita, betlemita, camita, efraimita, gabaonita, galaadita, sodomita, madianita, moabita, israelita, etc. El derivado adanida "descendiente de Adán" puede ser variante de adanita.

-ICO: aarónico, adánico, gedeónico. Del gr. Mōsaikós procede el español mosaico.

-EO. Se han transmitido a través del latín: amorreo, arameo, galileo, indumeo, nazareo.

-ENA. Sufijo que expresa semejanza: "una nariz jerusalena"

\footnotetext{
78 1605, López de Úbeda, La pícara Justina, p. 334.

${ }^{79}$ Góngora, Letrillas, p. 106.

${ }^{80}$ Iglesias Ovejero ve en el antropónimo Pedro un parónimo de los términos con los que rima en el Refranero: medro, pedo, pello, pelo, pero, perro. Véase Ángel Iglesias Ovejero, "El árbol paremiológico de Pedro", p.90.

81 1656, Francisco Bernardo de Quirós, Aventuras de don Fruela.

82 Joan Corominas y José Antonio Pascual, Diccionario Crítico Etimológico Castellano e Hispánico.

${ }^{83}$ La NGLE admite rivalidades léxicas entre -ADA y -ERÍA, -ADA y -AZO, -ADA y-ÓN. Con nombres bíblicos, el sufijo -ADA tiene la primacía.

${ }^{84}$ Rainer considera que los sufijos -ITA, -EO -ICO, entre otros, forman adjetivos deonomásticos de persona y que, en general, son no productivos y marginales: Franz Rainer, "La derivación adjetival", in Gramática Descriptiva de la Lengua Española, 3, coord. Ignacio Bosque y Violeta Demonte, Madrid, Espasa Calpe, 1999, p. 4621-4622.

85 David Pharies, Diccionario Etimológico de los Sufijos Españoles, Madrid, Gredos, 2002.

${ }^{86}$ 1605, Francisco López de Úbeda, La pícara Justina.
} 
NP-> V

Verbalizaciones en -EAR, como jeremiquear, no pertenecen al léxico culto, a diferencia de los adjetivos anteriormente citados. Este verbo es etimología popular del catalán gemegar o gemecar, cambiado en jeremiquear, jerimiquear por influjo de Jeremías y jeremiada 'gimotear, Iloriquear', que es voz de Andalucía, Cuba, Ecuador y República Dominicana ${ }^{87}$. El español de América también mantiene el verbo jesusear ${ }^{88}$.

\section{La periodización del léxico deonomástico: el caso de los nombres bíblicos lexicalizados.}

El cambio categorial experimentado por el nombre propio no es un fenómeno exclusivo de las lenguas modernas, lo conoce el latín ${ }^{89}$, y ha tenido continuidad romance ${ }^{90}$. Los topónimos también están implicados en la recategorización: la palabra galería ${ }^{91}$ se tomó del latín tardío galilaea 'atrio o claustro de una iglesia', que a su vez procede de Galilea ${ }^{92}$.

Pertenecen a los siglos XIII y XIV usos denominativos y metafóricos del NP Herodes, según los datos del CORDE (los Herodes y un Herodes respectivamente). El mismo corpus proporciona ejemplos de los siglos XV al XVII: Abel, Abraham, Adán, Ana profetisa, Barrabás, Benjamín, Caifás, Cirineo, David, Jacob, Jeremías, Job, Jonás, Judas, Lázaro, Magdalena, Marta, Matusalén, Mesías, Moisés, Pilatos, Salomón, Sansón, Satán se emplean como apelativos que remiten al personaje bíblico. Son posteriores Cristo (1885- 1887: "ni Cristo lo entendía", Pérez Galdós), Iscariote (18851887, "lo que bregué con aquel Iscariote", ibid.), Pilatos $^{93}$.

\footnotetext{
87 Joan Corominas y José Antonio Pascual, Diccionario Crítico Etimológico Castellano e Hispánico.

88 DRAE, 2014.

${ }^{89}$ Catonī, -ōrum 'partidarios de Catón de Utica'. Tomado de Santiago Segura Munguía, Nuevo diccionario etimológico. Latín- español y de las voces derivadas, Bilbao, Universidad de Deusto, 2012, 5a ed.

90 Ángel Iglesias Ovejero, 1999: "La proverbialidad del nombre propio y las figuras del refranero", Paremia, 8 (1999), p. 279-288.

${ }^{91}$ La forma popular galería es ilustrativa de la disimilación [I... $>1 . .$. r]..

92 Joan Corominas y José Antonio Pascual, Diccionario Crítico Etimológico Castellano e Hispánico.

93 Primeros testimonios: XIII-XIV: 1. XV-XVII: 24. XVIII-XX: 3. Total: 29 lemas. En la fase de selección del léxico de los nombres bíblicos se ha consultado un trabajo anterior: Consuelo y Celeste García Gallarín, Deonomástica Hispánica. Vocabulario científico, humanístico y jergal, Madrid, Editorial de la Universidad Complutense, 1997. El corpus inicial se ha ampliado considerablemente con nuevos datos obtenidos de los corpus mencionados.
} 


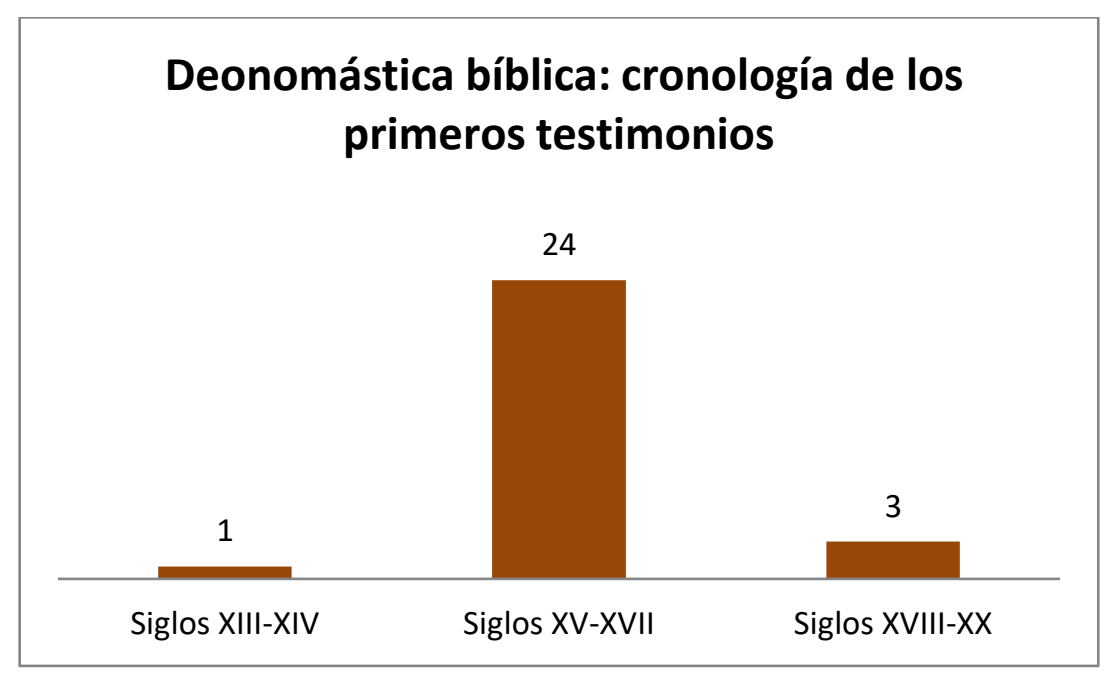

El cambio categorial se manifiesta en sintagmas de determinante y nombre propio apelativizado, con posibilidades de pluralizarse (los Abeles), también abundan las construcciones de ARTÍCULO + NP + DE (1) y las de ARTÍCULO + NP + RELATIVO (2). Se convirtieron en peculiaridad estilística de los seguidores del conceptismo literario, pero están atestiguadas en textos anteriores y han perdurado hasta nuestros días:

(1) "No le podían desconocer, que estos bellacones son los Caines del mundo" 94.

(2) Como si yo tuviera otra vida al cabo de un arca, o como si la que yo tenía me la hubiera dado el Pilatos que dio la sentencia. Notificómela un notario, tan buen cristiano que no me pidió albricias por la buena nueva ni derechos de lo procesado ${ }^{95}$.

En el Renacimiento, los escritores exploran en el legado de la tradición popular, en la Biblia, en la literatura, en la historia y otras fuentes, para buscar el simbolismo mitológico, iniciándose así la tematización de los mitos, pero es en el Barroco cuando se produce la modificación del tópico y cuando el tratamiento burlesco de la leyenda provoca la ruptura del sistema establecido; dicha innovación se manifiesta en las novelas picarescas del siglo XVII y en la poesía satírica de los grandes maestros de la literatura clásica. Estas fuentes son óptimas para realizar un estudio de la deonomástica desde el punto de vista histórico. Se amplían entonces las posibilidades de establecer ingeniosas relaciones entre un referente inicial y realidades muy dispares. La actividad creadora comporta un fuerte grado de audacia, de capacidad para establecer conexiones con el pasado y el presente. La ampliación de la base referencial es la principal consecuencia de la creatividad barroca.

\footnotetext{
94 1605, Francisco López de Úbeda, La pícara Justina, p. 229.

95 1646, anón., La vida y hechos de Estebanillo González.
} 


\section{Conclusiones}

a) La creación de prototipos de origen bíblico va ligada a la religiosidad popular, a la iconografía y al tratamiento de estos personajes en las paremias. Los usos propios de la lengua elaborada los han introducido autores que pueden extraer estos modelos de otras obras, leídas o contempladas individualmente.

b) Solo unos cuantos nombres de personajes bíblicos se han lexicalizado plenamente. Pertenecen a la deonomástica popular.

c) Debe contemplarse la posibilidad de que estas palabras de origen onomástico puedan pertenecer al léxico heredado, al adquirido o al mutiplicado. Se han descubierto usos exclusivos de las variedades del español.

d) El referente inicial puede confundirse con otros homónimos; la dificultad etimológica se incrementa en el caso de que el prototipo se forme a partir de usos denominativos (los juanes son campesinos).

e) La lexicalización de los nombres propios asciende considerablemente en el Barroco, cuando se extrema la intención de crear expresiones de efectos hiperbólicos, eufemísticos o humorísticos.

f) El campo del hombre ha sido el más beneficiado por la lexicalización de los nombres bíblicos. Los epónimos designan tipos morales y sociales. 